\section{Portal vein embolization as a complication of Histoacryl injection for a bleeding giant gastric ulcer}

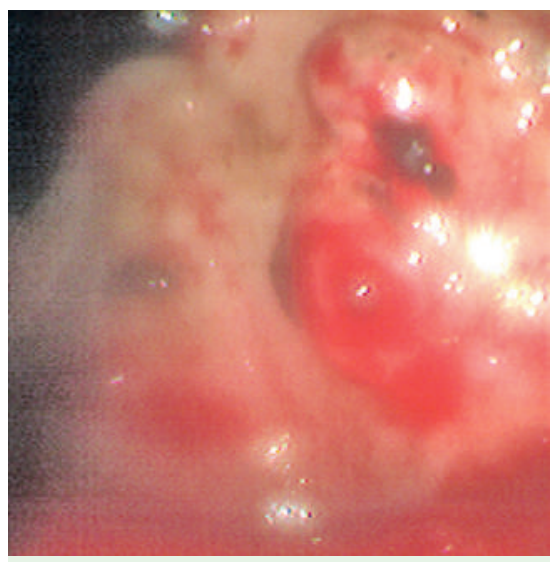

Figure 1 Endoscopic view showing the giant ulcer base on the posterior wall high in the body of the stomach. There was a large visible vessel coated by a red clot but with active oozing.

A 56-year-old man with schizophrenia presented with acute hematemesis. He had been taking nonsteroidal anti-inflammatory drugs frequently for headache. Emergency panendoscopy revealed a huge gastric ulcer on the posterior wall, high in the body of the stomach. The ulcer had a large visible vessel in its base. The vessel was coated with red clot but there was active oozing under the clot ( $\bullet$ Figure 1).

Considering the firm ulcer base and the large vessel, a clipping device was used to place two endoclips on both ends of the vessel. This did not stop the oozing, however. Despite various measures, including injection of saline and epinephrine, and repeated thermocoagulation with heater probe, bipolar hot biopsy forceps, and argon plasma coagulation, the oozing could not be stopped. Band ligation was not considered for the firm ulcer base. Eventually the bleeding was stopped by injection of $4 \mathrm{~mL}$ of a mixture of equal amounts of N-butyl-2-cyanoacrylate (Histoacryl; B. Braun, Melsungen, Germany) and Lipiodol (Laboratoire Guerbet, Aulnay-Sous-Bois, France). Although immediate hemostasis was achieved, massive hematemesis recurred 2 days later. The patient underwent surgery, when a giant penetrating ulcer extending to the liver bed was found. Moreover, an incidental finding of portal vein embolization was made when a computed tomographic scan was performed for the investigation of postoperative fever (๑ Figure 2).

Numerous trials have demonstrated the benefit of endoscopic intervention compared with medical management alone for acute nonvariceal upper gastrointestinal hemorrhage [1]. Endoscopic treatment modalities can be categorized into three groups: injection, thermal, and mechanical [2]. What is the cost of hemosta-

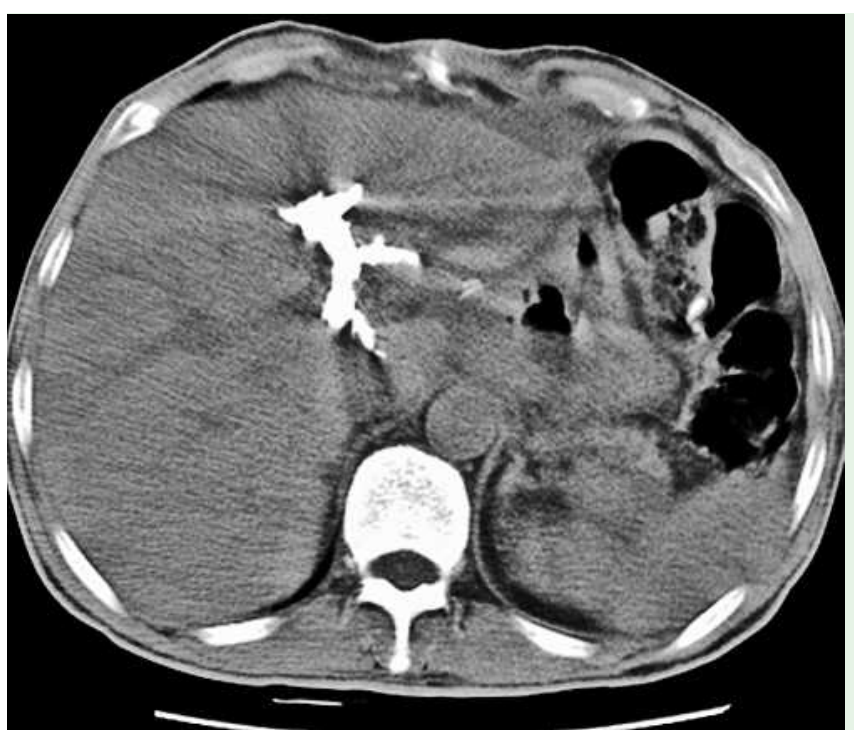

Figure 2 Computed tomography revealed the embolized portal vein was filled with radio-opaque material, which had been caused by a mixture of Histoacryl and Lipiodol. sis using these treatments, however? Can they damage adjacent organs?

Histoacryl injection for the treatment of varices is well established, despite its complications $[3,4]$, and it is used as a last resort before surgery in ulcer bleeding [5]. Vascular complications have rarely been reported. This case highlights the possibility of unnecessary iatrogenic embolization of an adjacent organ while treating a huge and deep ulcer.

Endoscopy_UCTN_Code_CPL_1AH_2AC

\section{C.-S. Fan, M.-S. Soon}

Department of Gastroenterology, Changhua Christian Medical Center, Changhua, Taiwan

\section{References}

1 Cook DJ, Guyatt GH, Salena BJ, Lame L. Endoscopic therapy for acute nonvariceal upper gastrointestinal hemorrhage: a meta-analysis. Gastroenterology 1992; 102: 139-148

2 Chung IK, Kim EJ, Lee MS et al. Bleeding Dieulafoy's lesions and the choice of endoscopic method: comparing the hemostatic efficacy of mechanical and injection methods. Gastrointest Endosc 2000; 52: 721 724

3 Shim CS, Cho YD, Kim JO et al. A case of portal and splenic vein thrombosis after histoacryl injection therapy in gastric varices. Endoscopy 1996; 28: 461

4 Cheng PN, Sheu BS, Chen CY et al. Splenic infarction after histoacryl injection for bleeding gastric varices. Gastrointest Endosc 1998; 48: 426- 427

5 Yo KY, Kum CK, Goh PM. Endoscopic hemostasis of upper gastrointestinal bleeding with histoacryl: last resort before surgery. Endoscopy 1996; 28: 256-258

\section{Bibliography}

Dol 10.1055/s-2007-966148

Endoscopy 2007; 39: E110

(c) Georg Thieme Verlag KG Stuttgart · New York . ISSN 0013-726X

\section{Corresponding author}

\section{C.-S. Fan, MD}

Department of Gastroenterology

Changhua Christian Medical Center

135 Nanhsiao Street

Changhua 500

Taiwan

Fax: +886-4-7228289

60909@cch.org.tw 